\title{
Transnational knowledge during the Cold War: the case of the life and medical sciences
}

The recent perspective in the history of science has emphasized the need to write transnational narratives based on a reciprocal treatment of global and local contexts (Subrahmanyam, 1997). This transnational approach abandons the nation as a unit of analysis, Eurocentric narratives, cultural-diffusion interpretations, and the rigid opposition of the categories "center" and "periphery" in order to explain the dynamics of transnational circuits and the global and local circulation of knowledge, people, instruments, and scientific practices (Brown et al., 2006). This rich approach problematizes the notion of "international science" and addresses pending issues, such as the precise definition of notions like circulation, reception, adaptation, and creativity. However, most studies on transnational science have focused on the eighteenth century and on naturalists. Little attention has been paid to developments during the Cold War, when the life sciences, public health, and politics intertwined, and donors and new and renewed bilateral and multilateral organizations played an important role in the organization and output of scientific work. A remarkable expansion of state-funded medical science and military patronage of scientific work in the life sciences occurred during the Cold War in industrialized and developing countries. The papers in this dossier share the same study framework, seeing the Cold War as a global and plural phenomenon that shaped international, national, and local conditions and decisions for scientific work in light of the rivalry between the United States and the Soviet Union. The Cold War affected not only science and technology related to the military and space races, but also research in biomedicine and other fields.

In the early 1950s, in the wake of the Hiroshima and Nagasaki bombings, extensive research and experimentation occurred in physics and chemistry. Ana Romero's paper is a reflection on instruments that circulated and travelled between Spain and Italy (radioactivity counters), and on the political power of these two nations in a world convulsed by the bipolarity that was established at the end of Second World War. According to the author, these instruments were used as mediators, establishing not only protocols on how to act inside and outside laboratories, but also networks of collaborations (Spain exchanged uranium for technical assistance), and participating in the making of nuclear energy and political power during the Franco regime. Instruments and techniques travelled along with agreements and contracts, changing laboratories, establishing research agendas, and making nuclear development more dynamic. They were used by nuclear policy authorities to demonstrate political power. Through the work of physicist María Aránzazu Vigón, daughter of General Vigón, a minister in the first cabinet of the Franco regime, Romero not only highlights how historicizing the instruments sheds light on circulation and 
transnational collaborations, but also show how gender issues affected the circulation of radiation counters, as Vigón was responsible for studying the construction and workings of radioactivity counters in Spain.

In the aftermath of Second World War, biology and medicine also witnessed intensive developments that gave rise to the field of biomedicine. New techniques and practices were developed within human heredity as a medical field, intended not only to characterize but also to understand differences among populations and their relation to the presence of certain diseases. These new practices also allowed classical notions to be re-conceptualized, such as race, genetic variation, and natural and human populations.

Erica Torrens, in her paper, discerns the genealogy and shift of the concept of race and the racialization of Mexican bodies to show the resulting novel visual culture from the merge of genetic knowledge with the phenomenon of racism during the second half of the twentieth century in Mexico. Artists and scientists first gave visionary expression to the discourse on racial hierarchy in eighteenth century Europe, setting up a powerful apparatus for manifestations of exclusion, racism, and xenophobia. These images circulated widely in Europe and its colonies, influencing debates on race and the formation of national identities. In Mexico, during the nineteenth century, the term "mestizo" appeared powerfully in the political discourse as a symbol of identity in the formation of the Mexican nation state and as a homogenizing center of national identity. To consider Mexico's local framework, Torrens first shows the process of racialization in this country and its shifts due to changing conceptions of race and technologies to study human evolution and variation; and second, by analyzing the impact of both racial theories and biomedical knowledge on the visualization of racialized bodies in educational materials used in Mexico today. The conclusion is worrisome, since there is a deeply entrenched racist perception of human groups, pushed most likely, and inadvertently, by Mexican scientific and government institutions.

Tito Carvalho's and Ana Barahona's papers deal with the characterization of natural and human populations. Carvalho addresses the Brazilian research done by the Russianborn American geneticist Theodosius Dobzhansky in the mid-1950s and locates it within the science of variation and politics of diversity. He shows the ways in which scientific figures in politics depended on ideas about the role of scientists in society that were advanced in parallel to the co-production of natural and social orders. Dobzhansky's work with tropical populations in Brazil was both fundamental for his articulation of the Modern Synthesis and a source of his support for liberal, cosmopolitan, and democratic principles in the context of Second World War and the race issue. Carvalho argues that Dobzhansky was as committed to the development of the modern theory of evolution as to the scientific representation of the world as a way to tackle pressing social and political issues and to raise questions about the scientist's role in spreading scientific rationality as a global political project. Meanwhile, Barahona's paper deals with the characterization of child and indigenous populations by Mexican physicians Salvador Armendares and Rubén Lisker in Cold War Mexico. Using Lock and Nguyen's and Anderson's ideas of populations as laboratories of knowledge production and sites of cognition, this paper depicts the stateof-the-art in population genetics in Mexico, the building of populations, the networks of 
international collaborations that allowed the import and adaptation of newly developed techniques, and the entangled histories that allowed Armendares and Lisker to bring cytogenetics and population genetics together, and to give human genetics its social life. These last two papers add significantly to our understanding of genetics in Brazil and Mexico by showing how the practice of population genetics in the tropics was the scientific basis for the politics of diversity in Brazil (in Carvalho), and how cytogenetics and population genetics were combined intellectually and institutionally in Mexico (in Barahona), at a time when biomedicine was emerging as a post-Second World War enterprise due to global concerns about the effects of nuclear radiation on human and natural populations at the intersection of nuclear physics and genetics after Second World War.

The idea for this dossier arose from the interaction of the authors during the symposium "Transnational Knowledge during the Cold War. The case of the life and medical sciences," held in Rio de Janeiro, Brazil, in July 2017, at the International Congress of the History of Science and Technology, organized by Ana Barahona and Marcos Cueto, whom I would like to thank for suggesting using the journal História, Ciências, Saúde - Manguinhos to circulate and provide visibility for our studies across borders.

\section{REFERENCES}

BROWN, Theodore M.; CUETO, Marcos; FEE, Elizabeth.

The World Health Organization and the transition from "international" to "global" public health.

American Journal of Public Health, v.96, n.1, p.62-72. 2006.

SUBRAHMANYAM, Sanjay.

Connected histories: notes towards a reconfiguration of early Modern Eurasia. Modern Asian Studies, v.31, n.3, p.735-762. 1997.

Ana Barahona

Professor, Department of Evolutionary Biology/Universidad Nacional Autónoma de México. Coyoacán - Mexico City - Mexico orcid.org/0000-0001-7765-6444 ana.barahona@ciencias.unam.mx 